\title{
Sociedades desplegadas
}

\author{
Mario TASCÓN*
}

Propuesto: 25 de abril de 2011

Evaluado: 4 de mayo de 2011

Aceptado: 6 de mayo de 2011

(Abstracts y palabras clave al final del texto)

Revueltas en Siria, movimientos prolibertades en México, opositores en Venezuela: algo está pasando y somos conscientes de que sólo lo estamos observando a través de la superficie de las pantallas de los ordenadores.¿Qué hay detrás? ¿Qué sucede más allá de esa cara plana a través de la que accedemos, sin entenderlo todavía, a la primera línea de la realidad, con la seguridad que nos da que en caso de peligro, de alerta, solo con pulsar la tecla de escape o cerrar la ventana del navegador volvemos de nuevo a la tranquilidad de nuestro hogar. Hace años el profesor Antonio Rodríguez de las Heras definía de esta forma el hipertexto:

Cuando pliegas una hoja de papel le das volumen. Lo que era una superficie, de dos dimensiones, por tanto, se transforma en un volumen de tres. En el espacio digital es posible ya no plegar el soporte, sino plegar el texto. El resultado de este ejercicio nuevo de papiroflexia, en el que lo que se pliega ya no es el papel, es el hipertextoํ.

Ahora, más allá del propio hipertexto que conforma los medios digitales, son las sociedades las que están adquiriendo una nueva forma mediante los pliegues que se producen en el hiperespacio. Sociedades que se conectan en puntos que no teníamos previstos y en los que hemos podido comprobar que se cumple la teoría de los seis grados de separación, aquella que predice que el número de pasos para conectar a una persona con otra cualquiera del planeta es de una media de seis, como había propuesto en el cuento Chains (1930) el escritor húngaro Frigyes Karinthy.

Rami Nakle, uno de los activistas sirios más conocidos en las últimas semanas, se encuentra a muy pocos pasos de distancia de cualquiera de nosotros, seguramen-

\footnotetext{
* Mario Tascón es periodista, experto en prensa digital, consultor y profesor en la Universidad de Navarra.

1 A. Martínez de las Heras. "Hipertexto". www. manualdeestilo.com/hipertexto/hipertexto (Consultada 7/06/2011)
} 
te no más allá de un par de tuiteros de distancia si uno sabe cuáles son los atajos de esa red que utiliza todo el mundo. Parece que el número de pliegues, en palabras del profesor de las Heras, con los que llegamos hasta Rami es mínimo. Esos dos pasos son miles de kilómetros en realidad porque Rami ahora se encuentra en la frontera del Líbano tras haber huido de Siria por las presiones de la Policía que, además, desveló su verdadera identidad haciéndole abandonar su nombre falso (Malath Omran) que ya no necesita.

Rami es uno más de una amplia red que se divide entre los que informan y los que publican en Internet. Es una pequeña pieza dentro de un universo de relaciones y conexiones reales y virtuales que están agitando y desestabilizando el mundo como lo hemos vivido. Nuevos modelos de relaciones grupales e intergrupales casi como no imaginábamos. Lealtades virtuales, uniones sin mediar relación física, comunicaciones textuales en las que nunca hubo una palabra. Nuevos modelos para grupos humanos, relaciones con pliegues (o pasos de separación) desconocidos.

\section{NUEVOS GRUPOS SOCIALES}

Las agrupaciones humanas en el mundo analógico empiezan a adquirir nuevas formas en este ejercicio de papiroflexia que proporciona la existencia de un mundo virtual paralelo al real. Así quien es empresario en la vida puede ser aventurero en la virtual, los oficinistas pasan a ser héroes y, algunas veces, los héroes bellacos. Y grupos humanos que vivían desconectados e indiferentes, en cuestión de segundos comparten conocimiento y se movilizan unidos frente a un bien, o a un enemigo, común.

Todo es posible en un mundo virtual en el que, tras cada pliegue, las personas adquieren nuevas características. También, cómo no, los grupos humanos.

Pero, además, el mundo virtual cada vez está más imbricado con el mundo real. Si Second Life fue un error por intentar emular el mundo real, las redes sociales, que no lo emulan sino que lo amplifican y lo extienden, han triunfado donde fracasó aquel "segundo" mundo con avatares híbridos medio-reales medio-virtuales.

Los conceptos de tiempo y espacio también cambian: las cosas suceden "al lado" por lejos que esté su origen físico.

Con estos pliegues asistimos a un fascinante cambio de paradigmas que sobrepasa con mucho el territorio de los chats y las pantallas dedicadas a Twitter.

La velocidad de circulación de los mensajes informativos en la actualidad no tiene parangón con la de otros tiempos. Uno de los sueños de las células comunistas hecho realidad: no se necesitan imprentas ni pegatinas ni folletos; todo se transmite a golpe de móviles, Twitter o Facebook. Y si no llega con los nuevos medios, los antiguos, atenazados por una crisis que les impide ser ellos mismos, amplifican los mensajes, muchas veces sin el menor ejercicio de comprobación, con lo que la repercusión de los mismos crece.

Y todo ello parece embocarnos a una nueva época con niveles diferentes de desobediencia civil, que está adquiriendo formas distintas dependiendo de los países y las sociedades, pero con un elemento común que ya no es la religión ni siquiera la 
ideología, el elemento universal ahora es el propio medio de transmisión del mensaje: la tecnología. McLuhan resucitado: el medio es, como poco, parte del mensaje.

La desobediencia civil tradicional y sus modos de actuar ha devenido en los movimientos modernos en los que Internet tiene un papel fundamental. Las sociedades civiles ahora protestan o, incluso, consiguen cambiar gobiernos o derribar dictadores con un nuevo tipo de herramientas en la lucha política: aquellas que les proporcionan las redes telemáticas.

El activismo en la red hunde sus raíces en el hackactivismo (hacker + activismo), que supone la utilización de herramientas y medios digitales para la realización de acciones que llamen la atención de la sociedad, para así intentar conseguir cambios políticos o legislativos.

Se basa en que quienes saben programar pueden alterar el correcto funcionamiento de las redes de comunicaciones o el propio Internet. Esas alteraciones llamarán la atención de la sociedad que conocerá así los motivos de las protestas. Muchas veces los hackactivistas son asociados a ciberterroristas pero, al igual que en el mundo analógico, subyacen las mismas diferencias (y profundas) que entre activistas y terroristas, por más que las manipulaciones del lenguaje de los gobiernos que atacan los derechos humanos y las libertades civiles intenten unificar ambas etiquetas. Algunas de las formas más conocidas de acciones del activismo hacker son:

- Desfiguraciones de webs. Se cambia la forma de la web introduciendo en la misma nuevos lemas, fotos cómicas, etc. Posiblemente fue lo que sucedió con el web de Moncloa realizado especialmente para la inauguración de la presidencia española de la Unión Europea cuando apareció de repente una fotografía del cómico inglés Mr. Bean insinuando la imagen del presidente Zapatero. Muchas de las desfiguraciones se realizan aprovechando agujeros de seguridad muy básicos que los administradores no han "tapado", pero el efecto estético es muy llamativo.

- Ataques de denegación de servicio. Se paraliza el sitio atacado a costa del envío masivo de peticiones de páginas web que consiguen que las máquinas que sirven las mismas no puedan hacerlo por saturación. Algunas veces la atención mediática que se consigue hace que miles de ciudadanos participen involuntariamente, cuando alertados a través de correo o de Facebook de que una determinada web está siendo atacada acuden en masa a ver qué pasa provocando más peticiones $\mathrm{y}$, por tanto, añadiendo más carga al sistema. Normalmente los que lanzan el ataque son dueños de verdaderos ejércitos de ordenadores "zombies", muchos de ellos de empresas o personas que no tienen ni la más mínima idea de que su ordenador es utilizado para esos fines. Parte del trabajo previo de los atacantes suele ser hacerse con ese control de computadoras, a través de programas específicos o consiguiendo el dominio de los programas con los que los administradores de sistemas legítimos atienden en remoto los ordenadores de una compañía o universidad. En un determinado momento esos ordenadores "zombies" despiertan y son utilizados en masa para "tumbar" la web objetivo. Han sido muy famosos los ataques a las 
webs de Visa y Amazon por partidarios de WikiLeaks (una web que ha revelado los cables con comunicaciones internas de las embajadas de EEUU en todo el mundo) para protestar por lo que consideraban un desafío de esas dos empresas a la libertad de expresión cuando una se negó a recolectar donaciones y la otra clausuró el servicio que tenía con la web a petición presuntamente del gobierno de los Estados Unidos.

- Mail bombing. Envío masivo de correos a una dirección determinada que consigue llenar el buzón del destinatario y bloquearlo. Lo senadores españoles sufrieron varios con motivo del pase por la cámara alta de la Ley de Economía Sostenible que incluía la "ley Sinde".

- Creación de software. Los desarrolladores preparan programas para proteger la identidad de los que protestan (muy útiles en países en los que los blogueros están perseguidos), programas para lanzar ataques contra otras organizaciones, o crean sitios de difusión de información (Wikileaks es el más famoso).

- Webs espejo. Una forma de protesta que consiste en clonar los contenidos de las webs que persiguen los gobiernos o las empresas para complicar su cierre e impedir la difusión de documentos. El caso de los miles de espejos de Wikileaks en todo el mundo, incluyendo alojamientos en máquinas de medios de comunicación (Liberation sin ir más lejos), es también una de las formas de hackactivismo más importantes.

A estas fórmulas clásicas se están incorporando otras variantes debidas a la suma masiva de personas a Internet. Nos encontramos con acciones coordinadas equivalentes al mail bombing para las que no hace falta tener una red de ordenadores esclavos porque los internautas se autoorganizan para enviar sus correos provocando el mismo efecto, quizás incluso un poco más intimidante, porque quienes reciben los correos electrónicos ven como uno a uno todos se corresponden con personas concretas.

Aparecen también nuevos fenómenos como las "turbas digitales" en las que en cuestión de horas alguien es "lapidado" por una masa (no anónima) de otros individuos que a través de sus cuentas de Twitter, por ejemplo, realizan todo tipo de escarnios — virtuales, eso sí- sobre la conducta del "pecador". Pedradas digitales contra enemigos virtuales parece un nivel diferente del que se produce en la calle cuando las piedras se lanzan contra la Policía y esta responde con pelotas de goma. ¿O estamos ante fenómenos tan interconectados que es sólo la novedad en algunos comportamientos la que nos impide ver la unión? ¿Hay tanta diferencia entre un grafiti y un tuit?

\section{EL CIBERACTIVISMO EN EL SIGLO XXI}

En unos encuentros en Madrid en La Casa Encendida titulados: "Internet y las revoluciones sociales del siglo XXI" se recopilaron una serie de conclusiones, como que los móviles son un arma mucho más importante todavía que la propia Internet 
para el activismo en Africa y Asia, ya que sólo un 2\% de la población tiene acceso a Internet, pero un $65 \%$ tienen un teléfono.

Los activistas poseen una clara desventaja en recursos frente a los gobiernos, especialmente los occidentales encabezados por EEUU que tiene un presupuesto de más de 300 millones de dólares para acciones de propaganda en Internet incluyendo identidades falsas.

Y en esos nuevos modelos de desobediencia civil y de protesta política se difunden consejos como los siguientes entre los ciudadanos convertidos en seguidores o participantes activos a través de las redes sociales:

Si grabas, oculta la cara de los testigos para que no los identifiquen luego.

Ten cuidado con la difusión de videos e ideas en redes que son estadounidenses y sus políticas de publicación tienen en cuenta los intereses de ese país.

Cuidado con conceptos como igualdad, democracia o libre acceso a redes como Twitter, Flickr o Youtube. Sus propietarios son empresas estadounidenses y, por tanto, las políticas de propiedad intelectual, de publicación y de protección de datos son afines a los intereses de aquel país.

Entre todos los intentos de control de los gobiernos, políticos y aparatos de los estados, los ciudadanos continúan encontrando nuevos atajos, nuevos pliegues en esta nueva configuración de las sociedades y de la lucha política. A su vez los ciberactivistas continúan alimentando con sus armas a las sociedades con información que se difunde en los nuevos ecosistemas informativos participados por nuevos y viejos medios. Y, de repente, aparece un viejo activista, Julian Assange, convertido en héroe popular, incluso alabado por los periodistas del final de una época como adalid del nuevo periodismo (?), aunque él se empeñe en jurar que es casi todo menos periodista. Esos pliegues sociales hacen que quien es uno de los hackactivistas más conocido pase de ser una cita en la Wikipedia a portada de la revista Time en cuestión de semanas.

Pliegues que hacen que en un segundo el web de VISA deje de funcionar y al siguiente, tras el bloqueo de un gobierno a los videos de You Tube, Facebook se convierta en una tele popular en la que miles de ciudadanos árabes vean en directo imágenes de la represión que está sucediendo a pocos metros de sus casas.

Pero lo importante no es solo que lo vean ellos, es que el resto del mundo también lo ve. La teoría de los seis pasos de separación no deja de ser una confirmación de que el mundo es un pañuelo, falta saber si el pañuelo es de papel y nos permite hacer papiroflexia como avanzaba de las Heras. 


\section{RESUMEN}

El autor revisa los principales cambios que alteran el panorama profesional y social de los medios de comunicación, analizando los nuevos riesgos y también las nuevas oportunidades que las tecnologías presentan al periodista profesional y a los grupos y la sociedad en los que vive.

Palabras clave: Tecnología digital, medios de comunicación, periodismo profesional, ciberactivismo, hackactivismo, nuevos grupos sociales.

\section{ABSTRACT}

The autor studies the main changes which alter the professional and social landscape in communication media, analysing the new dangers and the new opportunities that technologies offer to professional journalist and to the groups and societies in which he lives.

Key words: Digital technology, communication media, professional journalism, cyberactivism, hackactivism, new social groups.

\section{RÉSUMÉE}

L'auteur étudie les principaux changements que altèrent l'aspect social et professionnel de la communication des mèdias, en analysant les plus importants dangers ainsi que les nouvelles opportunités que les technologies offrent aux journalistes et aux groupes et sociétés dans lesquelles ils habitent.

Mots clé: Technologie digitale, médias de la communication, journalisme professionnel, cyberactivisme, hackactivisme, nouveaux groupes sociaux. 